https://helda.helsinki.fi

\title{
Threats from the air: damselfly predation on diverse prey taxa
}

\author{
Kaunisto, Kari M
}

2020-06

Kaunisto , K M , Roslin , T , Forbes , M , Morrill , A, Sääksjärvi , I E , Puisto , A , Lilley , T \&

Vesterinen, E 2020 , ' Threats from the air: damselfly predation on diverse prey taxa ' , Journal of Animal Ecology, vol. 89 , no. 6 , pp. 1365-1374 . https://doi.org/10.1111/1365-2656.13184

http://hdl.handle.net/10138/327294

https://doi.org/10.1111/1365-2656.13184

acceptedVersion

Downloaded from Helda, University of Helsinki institutional repository.

This is an electronic reprint of the original article.

This reprint may differ from the original in pagination and typographic detail.

Please cite the original version. 
2

3 Kaunisto K. M. ${ }^{1}$ Roslin T. ${ }^{2,3}$, Forbes M. R. ${ }^{4}$, Morrill A. ${ }^{4}$, Sääksjärvi I. E. ${ }^{1}$, Puisto A. I. E. ${ }^{1,3}$

4 and Vesterinen E. J. . $^{1,3}$

5

$6{ }^{1}$ Zoological Museum, Biodiversity Unit, University of Turku FI-20014, Turku, Finland.

$7 \quad{ }^{2}$ Department of Ecology, Swedish University of Agricultural Sciences, Uppsala, Sweden.

$8 \quad{ }^{3}$ Department of Agricultural Sciences, University of Helsinki FI-00014, Helsinki, Finland.

$9{ }^{4}$ Department of Biology, Carleton University, 1125 Colonel By Drive, Ottawa, Ontario, 10 Canada.

13 Correspondence to Kari Kaunisto

14 Address: Zoological Museum, Biodiversity Unit, FI-20014 University of Turku, Finland.

15 E-mail: kkauni@utu.fi

16

17

18

Running title: Vast predation by damselflies 


\section{Abstract}

1. To understand the distribution and strength of predation in natural communities, we need to quantify which predator species are eating which prey taxa. The recent adoption of DNAbased techniques has brought widespread characterization of predator diets with high taxonomic resolution. To further determine impacts of predators, we should next combine these DNA techniques with estimates of population size using mark-release recapture methods, and accurate metrics of individual food consumption.

2. In this study, we create a novel synthesis of the scale of predation pressure exerted by predatory damselfly species on their diverse prey taxa within an accurately defined area, resolving who is eaten by whom, how many prey individuals are consumed per predator, and to what extent the diet of individual predator species overlaps.

3. We identified the prey taxa composition of four damselfly species using DNA metabarcoding, and quantified damselfly population sizes by intensive mark-releaserecapture. By combining both approaches with predator-specific estimates of consumption rates, we estimate the summed predation pressure exerted by four damselfly species and its taxonomic distribution.

4. Across a 12-hectare study area, the damselfly species collectively consumed a prey mass equivalent to roughly $12,000,000$ small dipterans over two months. Each damselfly individual consumed 29\%-66\% times its own body weight in prey during its relatively short life (2-4.7 days) in the local population. This predation pressure was widely distributed across the local insect community, including 4 classes, 19 orders, and 84 families of arthropod prey. Different predator species showed extensive overlap in prey composition.

5. Our results suggest that relatively small damselflies exert a vast predation pressure on local prey populations and species assemblages. Given high local population size and high 
43 consumption rates per individual, the local damselfly community consumes a massive 44 amount of prey invertebrates.

45 6. Our synthesis of the population size, per-capita consumption rate and taxonomic 46 distribution of predation identify damselflies as a dominant predator group-harvesting insects 47 from the air. As a key prediction, we suggest that the experimental removal of damselflies 48 will reveal the same type of imprints as recently revealed for vertebrate predators including 49 birds and bats. 
Introduction

51 How different trophic levels impact one another is one of the key conundrums of modern ecology (Ings et al. 2009; Thompson et al. 2012). Recent studies of food web structure attempt to quantify not only who eats whom from a qualitative perspective, but also how frequently each type of predation event occurs (Roslin \& Majaneva 2016). While such targeted quantification of trophic links will elucidate the strength of direct ties between predators and potential prey, there is also potential for indirect effects through shared predators and prey (Schmitz \& Suttle 2001; Montoya et al. 2009). However, studies typically isolate a given module of the community from its whole biological context. To arrive at a comprehensive metric of predation pressure across the full range of prey taxa is notoriously difficult (Pocock, Evans \& Memmott 2012). More often, the interaction of single predator species with single prey species is targeted, relating consumption rates to prey size and prey density, and to determine whether a single predator species can regulate its prey species or even cause its local extirpation (Royama 2012).

The majority of current theory on predator-prey dynamics is based on the assumption of a tight linkage between a single predator and prey species, resulting in Lotka-Volterra dynamics and providing scope for classic population cycles (Royama 2012). Yet, even classic predator-prey species pairs and population cycles have been shown to be part of more complex food webs (e.g. Stenseth et al. 1997). This complexity calls for a re-evaluation of the community-level context of predator-prey dynamics, and for a new empirical assessment of the taxonomic distribution and overall predation pressure exerted by abundant predator taxa within larger communities (Holt 2009; Montoya et al. 2009). Only by embarking on such a challenging, yet essential characterization of predation in a community context, will we ever acquire the satisfactory understanding of predator-prey dynamics in nature and its population and community-level consequences. 
What has hampered the community-level dissection of predator-prey relations has long been the difficulties associated with assessing the dietary composition of predatory species (Roslin \& Majaneva 2016; Alberdi et al. 2018). Recently, DNA-barcoding techniques have opened new ways for studying, which prey species predatory species are eating in the wild (Vesterinen et al. 2013). Furthermore, these new DNA-based tools for diet analysis offer scope for identifying the full diet of focal predators (Kaunisto et al. 2017; Vesterinen et al. 2018; Eitzinger 2019; Rytkönen 2019). Now that we can identify the taxonomic distribution of prey species, we can begin to assess which species and species assemblages are affected by predation. Yet, to arrive at a satisfactory, community-level understanding of predation pressure, these estimates should be combined with two other pieces of information: the abundance of predators and the food consumption of each individual. For both items, recent methodological developments have brought important advances. The last 30 years have seen a rapid proliferation of advanced methods for making more use of Mark-Release-Recapture (hereafter MRR) data, including the sensitive estimation of population size, its temporal variation and local demographic rates (Lebreton et al. 1992; Cooch \& White 2018). Also, metabolic theory and parameterized models for estimating individual consumption based on predator-prey body size (Yodzis \& Innes 1992) or allometric (Gillooly et al. 2001) relations have regained traction (e.g. Pettersen et al. 2019).

93 Together, these three lines of research offer a novel synthesis of the community-level 94 distribution and strength of predation by different taxa on their prey taxa. Yet, to our knowledge, these three developments have not been brought together to quantify the predatory imprint of presumed-ecologically dominant predator taxa on their prey taxa, 97 species assemblages or focal communities.

As larvae and adults, odonates are largely visual predators - adults deploy various hunting strategies including active foraging flights, sit-and-wait strategies coupled with sullying 
100 flights and the gleaning of prey from vegetation (Corbet 1999). Yet, although predatory

101 behaviour of the odonates is well known, detailed research on adult odonate foraging is

102 scarce (but see e.g. Baird \& May 1997; Kaunisto et al. 2017). There are many large

103 information gaps in the study of odonate predation including the diets of predatory species

104 overlapping in space and time, and their combined impact on prey species, populations and 105 communities.

106 To approach such information gaps is not an easy task - their resolution requires information

107 on diets of different predator species, their survivorship and population size estimates of both 108 predators and prey. With this study, we address some of these knowledge gaps. We 109 characterize the taxonomic range and quantitative distributions of prey use by metabarcoding

110 a large sample of damselflies' faeces collected 'clean' from live individuals. To estimate the

111 population size and adult lifespan of these damselflies, we conduct a MRR study. We are able

112 to quantify predation in a community context by combining demographic information of

113 predator species with daily rates of prey consumption, weight information of focal damselfly

114 species extracted from literature and weight information on prey taxa. Overall, our study

115 reveals adult damselflies as key top predators of the insect world, exerting a vast predation

116 pressure of a wide range of aquatic and terrestrial arthropods.

\section{Materials and methods}

118 To assess the predation pressure of damselfly species on their prey, we target the four most 119 common predatory species at our study site in Southern Finland (located at ETRS-TM35FIN

120 N: 67118; E: 2460). All four species belong to family Coenagrionidae: Coenagrion

121 lunulatum (Charpentier, 1840), C. hastulatum (Charpentier, 1825), and C. pulchellum 122 (Vander Linden, 1825) and Enallagma cyathigerum (Charpentier, 1840). These species feed 123 mainly on dipteran prey during open foraging flights and by gleaning (Corbet 1999; Kaunisto 124 et al. 2017). Only sexually mature, i.e. adult-coloured and hard-winged individuals were 
included in the study. In the following sections, methods are explained briefly with full

126 details in the electronic supplementary material (supplementary material S1, Detailed

127 material and methods).

\section{Sampling and study site}

129 To assess the population sizes and survival rates of the focal species, we conducted a MRR

130 study of the damselfly populations associated with a freshwater pond of approximately $600 \mathrm{~m}$

131 x $200 \mathrm{~m}$ (12 ha). During the MRR study on 1 June and 2 June, we collected an additional 185

132 individuals (20-26 males and females from each species) for faecal DNA analysis.

\section{Molecular dietary analysis}

134 To establish the diets of focal species, we used established metabarcoding protocols for

135 dragonflies building on earlier optimization (Kaunisto et al. 2017). To amplify mitochondrial

136 COI gene, we used ZBJ-ArtF1c and ZBJ-ArtR2c (Zeale et al. 2011) and for insect 16S gene,

137 we used Ins16S-1F and Ins16S-1Rshort after Clarke et al. (2014). The detailed protocol is

138 available in supplementary material S1 (Detailed materials and methods: Description of

139 molecular methods). After sequencing, the reads separated by each original sample were

140 uploaded on CSC servers (IT Center for Science, www.csc.fi) for bioinformatic analysis.

141 Detailed bioinformatics applied is available in the supporting material (Supplementary

142 material S1, Detailed material and methods: Bioinformatics). Labelled raw reads, ZOTUs,

143 and zotu-tables are available in the Dryad Digital Repository: https://doi.org/XXX.

\section{Data analysis}

145 DAMSELFLy POPULATION PARAMETERS - To convert MRR data into estimates of population

146 size and its temporal variation, we used the MARK software (version 9, Cooch \& White

147 2018). We applied Jolly-Seber methods under the POPAN parameterization (Lebreton et al.

148 1992). For details, see Supplementary material S1 (Detailed material and methods: MRR 
estimates). Estimates of time-specific population size were then integrated over time and fed into downstream analyses (see INDIVIDUAL AND COMMUNITY-LEVEL CONSUMPTION RATES,

151 below).

152 Prey IDENTITIES AND ABUNDANCES - We identified prey to the family level, using locusspecific criteria (COI and 16S). For details, see Supplementary material S1, Detailed material and methods: Prey taxa). In earlier work offering proof-of-concept (Kaunisto et al. 2017), we used prey frequencies (fraction of droppings in which read was present) rather than read abundances (number of sequencing reads of this prey taxon) as measures of trophic link strength. As recent work suggest that a reliance on the presence-absence data may be more misleading than the use of read abundances (Deagle 2019; Lamb 2019), we used read counts, using relative read abundance (RRA) calculated for each prey taxon in each sample as a proxy of prey-specific biomass consumed (Appendix S1, Detailed material and methods: Eqn S1 Vesterinen et al. 2018; Deagle 2019).

PREDATOR-SPECIFIC PREY USE - To visualize the trophic interactions structures resolved by the molecular data, we used package "bipartite" (Dormann 2009) implemented in program R

164 (R Core Team 2018). To illustrate the prey sharing between the four odonate species, we used a Venn diagram constructed using R package 'VennDiagram' version 1.6.20 (Chen \& Boutros 2011). To test for effects of species and sex of predator on variation in prey taxon composition, we used PERMANOVA (Anderson 2001). To visualize the comparison of prey use among predator taxa, we performed a principal component analysis (PCA) based on

169 Bray-Curtis similarity (Bray \& Curtis 1957; Legendre \& Legendre 2012) of the taxonomic 170 composition of prey detected in each faecal sample.

171 INDIVIDUAL AND COMMUNITY-LEVEL CONSUMPTION RATES - To calculate the speciesspecific consumption rate of predator $i$ across all prey species, we used the following equation: 
175 Here, $W$ stands for individual predator mass, $R$ for daily consumption rate, $N_{i}$ for predator

176 population size, and $L$ for the estimated longevity of each individual predator. To convert $P_{i}$

177 to an estimate of the number (count) of average-sized prey individuals consumed, we divide

$178 P_{i}$ by $b_{w}$, i.e. average individual prey biomass. To derive overall prey consumption, we

179 summed across the four predator species $i$. Parameter values for $W$ and $R$ were extracted from

180 recent literature, whereas values of $N_{i}$ were adopted from MRR estimates (see Results). As a

181 representative estimate of $b_{w}$, we made 9 and 351 weightings from randomly-selected

182 individuals, of two most common prey families, Cecidomyiidae and Chironomidae, 183 respectively.

\section{Results}

\section{Predator population size}

186 Altogether we marked and released 1,341 individuals of the four damselfly species, of which

187 we later made 32 recaptures. The longest time spans observed between mark, release and 188 recapture were 14, 15, 18, and 17 days for C. lunulatum, E. cyathigerum, C. hastulatum and 189 C. pulchellum, respectively.

190 The Jolly-Seber models suggested the smallest overall population size for C. hastulatum,

191 while E. cyathigerum was the most abundant species, with estimates varying from 5,960 to 192 22,540 (Supplementary material S1, Additional results: Table S1). Average residency time in 193 the population ranged from 2.07 days (C. lunulatum) to 4.68 days (E. cyathigerum; Table 194 S1).

195 Across individual sampling dates, estimates and temporal patterns of damselfly population

196 sizes varied widely across the four species of interest (Supplementary material S1, Additional 197 results: Fig. S1). C. lunulatum population estimates began near 2,000 individuals, but 
dropped to approximately zero by the halfway point of sampling. Abundance estimates of

199 both $C$. hastulatum and $C$. pulchellum began at less than 500, quickly increased to their

200 respective maxima, and then decreased gradually throughout the rest of the season. Only $E$.

201 cyathigerum abundance estimates generally increased across most of the entire sampling 202 period (Fig. S1).

203

204

205

206

207

208

209

210

211

212

213

214

215

216

217

218

219

220

221

222

\section{Prey composition}

The sequencing run yielded 16,188,489 quality-controlled paired-end reads. After bioinformatic pipeline and subsequent filtering, the remaining (COI: 449573 COI; 16S: 478 202) reads were assigned to prey families. Practically all of the filtered COI reads (99.6\%) could be identified to family level prey. For filtered $16 \mathrm{~S}$ reads, $\sim 31 \%$ were identified as target prey, however, this result should still be considered good when amplifying arthropod prey DNA mixed with arthropod predator DNA, see for example Pinol et al. (2014), where only $6 \%$ of reads were assigned to prey in a study without blocking primers. In this study, the most common prey order was Diptera, and the most abundant prey families were Cecidomyiidae and Chironomidae (Fig. 1). The four predator species showed extensive overlap in the prey use (Supplementary material S1, Additional results: Fig. S2). The most common prey taxa (Cecidomyiidae and Chironomidae) were widely consumed by all odonate species, and by both sexes (Supplementary material S1, Additional results: Fig. S3). PERMANOVA showed significant, but weak differences between predator species (ADONIS: $\mathrm{R}^{2}=0.013, \mathrm{P}=0.005$; Supplementary material $\mathrm{S} 1$, Additional results: Table S2) and sexes (ADONIS: $\mathrm{R}^{2}=0.038, \mathrm{P}=0.030$; Table S2). However, pairwise PERMANOVA confirmed that prey assemblage differed only between E. cyathigerum and C. pulchellum (Supplementary material S1, Additional results: Table S3). Where slight differences in diet were found among females and males in different species (Predator $\mathrm{x}$ Sex: $\mathrm{R}^{2}=0.03, \mathrm{P}=$ 0.035; Table S2), samples from the same predator species or sex did not detectably cluster 
together in the visual PCA ordinations (Supplementary material S1, Additional results: Fig. S4).

\section{Predation rates quantified}

226 Based on the information compiled in this study and from the literature, we were able to 227 parameterize Eqn 1 (above) as follows:

W, INDIVIDUAL PREDATOR MASS - All of our focal damselflies are very similar in size and weight. According to Ilvonen and Suhonen (2016), the weights of our focal damselflies $C$. hastulatum, C. pulchellum and E. cyathigerum, are $33.9 \mathrm{mg}$ (s.e. $1.3, \mathrm{n}=22$ ), $36.1 \mathrm{mg}$ (s.e. $1.3, \mathrm{n}=22$ ) and 35.4 (s.e. $1.3, \mathrm{n}=22$ ), respectively. The fourth focal damselfly species, Coenagrion lunulatum, was not directly weighed but since its average length matches that of C. hastulatum (Karjalainen 2010), we used the weight of that species, i.e. $33.9 \mathrm{mg}$, as an accurate proxy.

$\boldsymbol{R}$, DAILY CONSUMPTION RATE - For perching odonates, Corbet (1999) have shown individuals to consume on average $14 \%$ of their own body weight per day. This estimate is roughly consistent with other estimates reported in the literature: McVey: $12.5 \%$, Higashi: 12.75\%, Fried \& May: 12.5\%, Mayhew: 19\% (Higashi 1973; Fried \& May 1983; McVey 1985; Mayhew 1994). Thus, we adopt $14 \%$ as our estimate of $R$.

$\boldsymbol{b}_{\boldsymbol{w}}$, AVERAGE INDIVIDUAL PREY BIOMASS - The average fresh weight per individual of the two most common prey families was for $0.063 \mathrm{mg}(\mathrm{n}=9, \mathrm{SD} \pm 0.055 \mathrm{mg})$ Cecidomyiidae and $0.154 \mathrm{mg}(\mathrm{n}=351, \mathrm{SD} \pm 0.182 \mathrm{mg})$ for Chironomidae.

243 Across damselfly species, this yields the following species-specific estimates for the four

244 damselfly species: C. lunulatum (75,603 mg), C. hastulatum (75,775 mg), C. pulchellum 245 (117,685 mg), and E. cyathigerum (523,206 mg; Supplementary material S1, Additional 246 results: Eqns S2a-d). 
247 Across all species, this sums to $792,270 \mathrm{mg}$. Dividing by the average size of prey, $b_{w}$, this

248 amounts to $12,575,727$ cecidomyiids, or 5,144,616 chironomid individuals consumed per 249 season. Given an estimated average life span of ca 4 days (Table S1), each individual 250 damselfly is likely to consume prey mass equal to an average of 75 cecidomyiids per day and 251 a total of 301 cecidomyiids during its adult life.

\section{Discussion}

253 Our results suggest that damselflies exert a massive predation pressure on their prey species, 254 and will leave a key imprint on local insect populations, species assemblages and 255 communities. These findings build from the fusion of advances in molecular ecology, markrelease recapture methods and metabolic theory. The synthesis of these three fields frames the study of predation on arthropod prey in a community context, and suggests fruitful avenues for future research. Below, we discuss these avenues in further detail.

A new synthesis of new methods and classic ecological tools

260 The insights presented in this study build on multiple methodological advances combined in a new way. Recent advances in DNA-based diet analysis have allowed the qualitative description of diet contents across a range of taxa, information not attainable with traditional techniques (Roslin \& Majaneva 2016; Roslin et al. 2019). We are now advancing to the stage of quantification of diet contents. This approach involves not only quantifying the amount of prey in the diet (Deagle 2019; Lamb 2019), but the fusion of molecular quantification with more classical types of abundance estimates. In the current study, we combine quantitative

267 information on prey use gleaned from molecular data with insight from quantitative models

268 of MRR data (Lebreton et al. 1992; Cooch \& White 2018), used to derive estimates on population sizes of predatory species. Applying metabolic functions to link individual 
prey items consumed by our four focal damselfly species at our focal study site. This is an exciting advance, made possible by a new use of molecular data.

\section{Predation by damselflies is quantitatively vast and taxonomically widespread}

274 The current findings show damselflies as generalist predators with a wide variety of prey taxa. Dietary segregation among species and sexes proved weak. High overlap in niche space has also been observed in the North American genus Enallagma, consistent with the extensive sharing of prey by the current set of damselfly species (Siepielski et al. 2010). Overall, the odonates feed on a very high number of prey taxa, tapping widely into the prey community available at the site (Fig. 1). Besides being taxonomically widespread, we also show that the overall predation rate exerted is high, and that the typical prey of damselflies are small dipterans. Thus, relatively large odonates feed on relatively small dipterans with a predator-prey body mass ratio of over $260-1$. This finding is consistent with the observations of Baird and May (1997). Using traditional techniques such as visual monitoring of predators and prey, these authors reported that of the prey items captured by the dragonfly Pachydiplax longipennis (Burmeister, 1839), only $3 \%$ exceeded $1.47 \mathrm{mg}$.

Our study is important because top predators are thought to affect the food web at lower trophic levels in many ways, e.g. via trophic cascades, often resulting in dramatic changes in species composition (Estes et al. 2011; Van Allen et al. 2017). The high predation rates reported here suggest strong community-level impacts of damselfly on the local prey communities. While our rough estimates of the number of prey items consumed in just a few hectares are staggering (hundreds consumed per predator individual during its life time,

292 hundreds of thousands consumed per damselfly species during its flight period, and millions consumed per season by the damselflies combined), there are several reasons why the realized number of prey items is likely to be even higher than our current estimates.

295 Damselflies tend to discard less nutritious parts of their prey before ingestion (reviewed in 
296 Corbet 1999). Moreover, we only included adult damselflies into this study, but newly

297 emerged individuals have also been shown to actively hunt for prey (reviewed in Corbet 298 1999). Furthermore, our focal damselfly species are among the smallest odonates, whereas 299 e.g. another rather common dragonfly of our study area, the Brown Hawker Aeshna grandis

300 (Linnaeus, 1758), has a body mass of nearly a gram (mean $873.1 \mathrm{mg}$, S.E. $29.5 \mathrm{n}=25$ )

301 (Ilvonen \& Suhonen 2016). As a consequence of their heavier bodies, larger dragonflies will consume prey in considerably higher numbers and/or mass than their smaller relatives.

\section{Predation by damselflies in a community context}

304 Our findings reveal the main predators of the airborne arthropod community to be widely generalist predators. These findings are consistent with those from a pilot study (Kaunisto et al. 2017), which focused on three, likewise common odonate species differing in their life cycles and body size. Kaunisto et al. (2017) were able to demonstrate that different odonates overlap extensively in their prey use - not only with each other, but also with major diurnal and nocturnal airborne predators including birds and bats. The current study validates these results but significantly enriches the picture. Where previous work resolved the taxonomic

311 distribution of odonate predation (Kaunisto et al. 2017), the current study adds important

312 detail by revealing the vastly high predation pressure dissipated through the many links.

313 While even the simplest of food webs are usually complex (Wirta et al. 2015), with species

314 linked by diverse connections (Williams \& Martinez 2000), the predator-prey food web 315 detected for our focal damselflies and their prey is a highly connected one. Here, tight coupling between individual predator-prey taxa/species pairs seems the anomaly rather than

317 the rule. In such thoroughly linked systems, an increase in the predator may result in little 318 trophic cascades, simply because the elevated predation pressure is dissipated through so 319 many channels (Visakorpi et al. 2015). Dissecting community-level predation patterns is thus 320 a key precondition for understanding predator-prey dynamics in real, complex food webs. 


\section{Conclusions}

322 As the basic building block needed to understand the forces regulating animal populations, 323 and to estimate flows of energy and matter through food webs, we need sound estimates of 324 who is eating whom and in what quantities. Our results suggest that even small damselflies exert a massive predation pressure on their prey species, and will leave an imprint on local insect communities. What we lack are local estimates of prey populations, their reproductive rates and the relative direct and indirect contributions of damselfly predation as compared to other forces on dynamics of prey populations. Needless to say, such information is difficult to obtain, but might eventually be reconstructed from local emergence traps, MRR studies of

330 prey species and labor-intensive fieldwork. We hope that our study stimulates the quantification of key variables helping to resolve food web linages and dynamics. Our current estimates take an essential first step towards understanding of top-down versus bottom-up regulation of insect communities, and should next be supplemented by numerical estimates of

334 prey populations and of their demographic rates. A satisfactory understanding of predation pressure can only be achieved through these steps, in which context the combination of novel, DNA-based techniques with classical tools offer key catalysts. As a key prediction, we suggest that the experimental removal of damselflies will reveal the same type of impact on the ecosystem as recently revealed for vertebrate predators including birds and bats (Van Bael, Brawn \& Robinson 2003; Mooney et al. 2010; Mantyla, Klemola \& Laaksonen 2011;

340 Maine \& Boyles 2015).

\section{Acknowledgements}

342 The study was financially supported by the Finnish Cultural Foundation (KMK), Ella and

343 Georg Ehrnrooth foundation (KMK), Societas Entomologica Helsingforsiensis (KMK), Emil

344 Aaltonen foundation (KMK and EJV), and Jane and Aatos Erkko Foundation (EJV and 345 AIEP). This study was also supported by Finnish Functional Genomics Centre, University of 
346 Turku and Åbo Akademi and Biocenter Finland. We acknowledge CSC - IT Center for

347 Science Ltd., Espoo, Finland, for the allocation of computational resources. We would like to 348 thank Bess Hardwick and Tea Huotari for their valuable help in this work. 
351

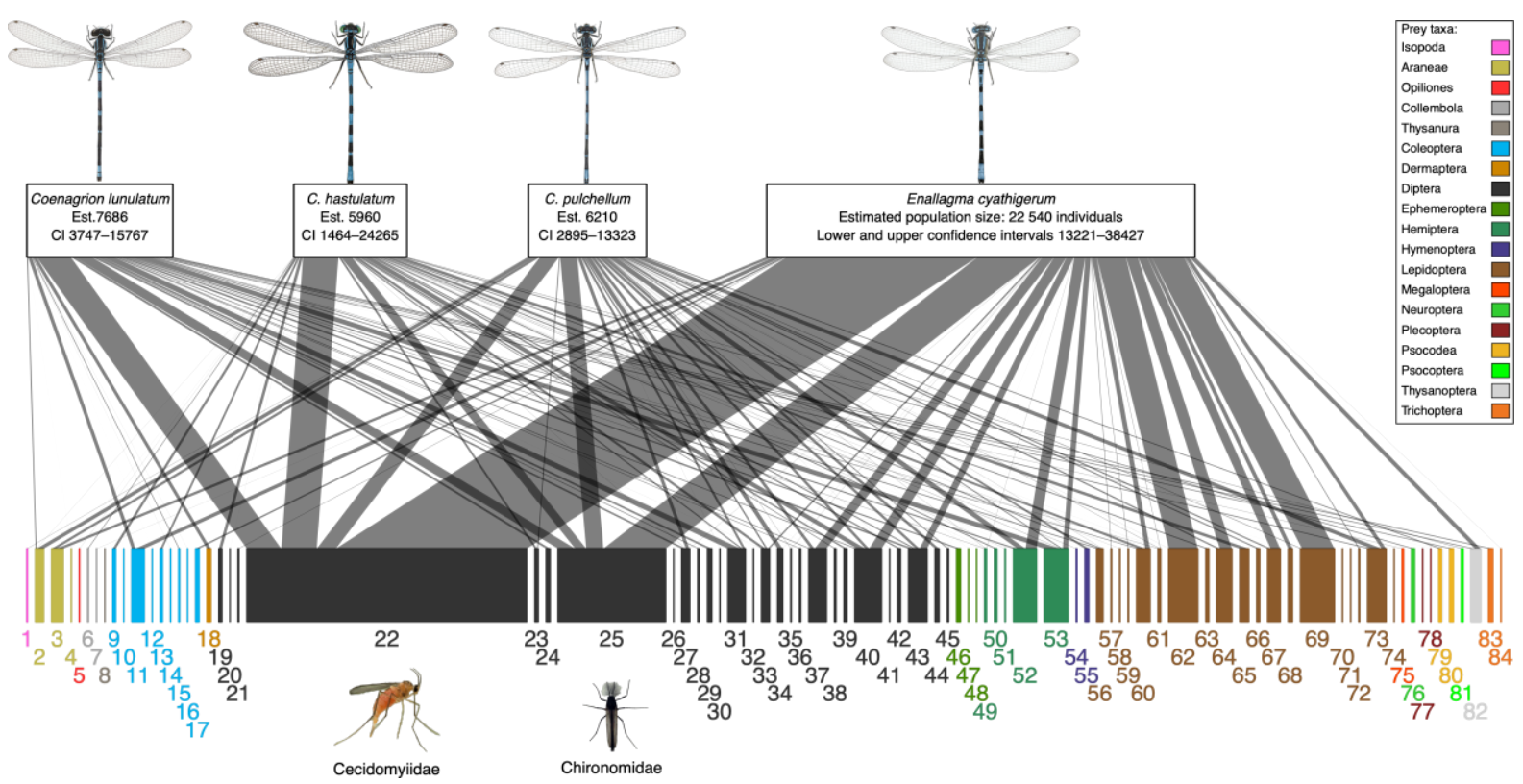

352 Figure 1. Visual representation of the taxonomic distribution and quantified strength of trophic links from each of our four focal odonate species to their prey. The blocks in the upper row represent predators, with their size scaled to represent the estimated population size. The blocks in the lower row represent prey families, with two most common prey families highlighted. A line connecting a predator with a prey represents detected predation events, and the thickness of the line represents the relative read abundance (RRA) of each predation record (Supplementary material S1, Detailed material and methods: Eqn S1). See the "Data analysis" in the main text for details on the RRA. The numbers below the lower blocks correspond to the prey family numbers (Supplementary material S1: Table S4). Photo

361 credits: Göran Liljeberg \& Hallvard Elven, Artdatabanken.no (CC BY-SA 3.0, Odonata),

362 Hallvard Elven, Artdatabanken.no (CC BY-SA 4.0, Cecidomyiidae, modified); František Šaržík, biolibs.cz (CC-BY, Chironomidae, modified). 
Alberdi, A., Aizpurua, O., Bohmann, K., Gopalakrishnan, S., Lynggaard, C., Nielsen, M. \& Gilbert, M.T.P. (2018) Promises and pitfalls of using high - throughput sequencing for diet analysis. Molecular Ecology Resources, Early view.

Anderson, M.J. (2001) A New Method for Non-Parametric Multivariate Analysis of Variance: Non-Parametric MANOVA for Ecology. Austral Ecology, 26, 32-46.

Baird, J.M. \& May, M.L. (1997) Foraging behavior of Pachydiplax longipennis (Odonata: Libellulidae). Journal of Insect Behavior, 10, 655-678.

Bray, J.R. \& Curtis, J.T. (1957) An ordination of the upland forest communities of southern wisconsin. Ecological Monographs, 27, 326-349.

Chen, H. \& Boutros, P.C. (2011) VennDiagram: a package for the generation of highlycustomizable Venn and Euler diagrams in R. BMC Bioinformatics, 12.

Clarke, L.J., Czechowski, P., Soubrier, J., Stevens, M.I. \& Cooper, A. (2014) Modular tagging of amplicons using a single PCR for high-throughput sequencing. Molecular Ecology Resources, 14, 117-121.

Cooch, E. \& White, G. (2018) Program MARK: A gentle introduction. Available from: http://www.phidot.org/software/mark/docs/book/.

Corbet, P.S. (1999) Dragonflies: behaviour and ecology of Odonata. Revised edition. Harley Books, Colchester.

Core, T.R. (2018) A Language and Environment for Statistical Computing. Vienna, Austria.

Deagle, B.E., Austen C. Thomas, Julie C. McInnes, Laurence J. Clarke, Eero J. Vesterinen, Elizabeth L. Clare, Tyler R. Kartzinel, and J. Paige Eveson (2019) Counting with DNA in Metabarcoding Studies: How Should We Convert Sequence Reads to Dietary Data? Molecular Ecology, 28, 391-406.

Dormann, C.F., J. Frund, N. Bluthgen, and B. Gruber (2009) Indices, Graphs and Null Models: Analyzing Bipartite Ecological Networks. The Open Ecology Journal, 2, 7 24.

Eitzinger, B., N. Abrego, D. Gravel, T. Huotari, E. J. Vesterinen, and T. Roslin (2019) Assessing changes in arthropod predator-prey interactions through DNA based gut content analysis-variable environment, stable diet. Molecular Ecology, 28, 266-280.

Estes, J.A., Terborgh, J., Brashares, J.S., Power, M.E., Berger, J., Bond, W.J., Carpenter, S.R., Essington, T.E., Holt, R.D., Jackson, J.B.C., Marquis, R.J., Oksanen, L., Oksanen, T., Paine, R.T., Pikitch, E.K., Ripple, W.J., Sandin, S.A., Scheffer, M., Schoener, T.W., Shurin, J.B., Sinclair, A.R.E., Soule, M.E., Virtanen, R. \& Wardle, D.A. (2011) Trophic Downgrading of Planet Earth. Science, 333, 301-306.

Fried, C.S. \& May, M.L. (1983) Energy expenditure and food intake of territorial male Pachydiplax longipennis (odonata, libellulidae). Ecological Entomology, 8, 283292.

Gillooly, J.F., Brown, J.H., West, G.B., Savage, V.M. \& Charnov, E.L. (2001) Effects of size and temperature on metabolic rate. Science, 293, 2248-2251.

Higashi, K. (1973) Estimation of the food consumption for some species of dragonflies.I. Estimation by observation for the frequency of feeding flights of dragonflies. Rep. Ebino.Biol. Lab., 1, 119-129.

Holt, R.D. (2009) Toward a trophic island biogeography. The theory of island biogeography revisited. Princeton University Press, Princeton, New Jersey, USA. 
Ilvonen, J.J. \& Suhonen, J. (2016) Phylogeny affects host's weight, immune response and parasitism in damselflies and dragonflies. R. Soc. open sci, 3.

Ings, T.C., Montoya, J.M., Bascompte, J., Bluthgen, N., Brown, L., Dormann, C.F., Edwards, F., Figueroa, D., Jacob, U., Jones, J.I., Lauridsen, R.B., Ledger, M.E., Lewis, H.M., Olesen, J.M., van Veen, F.J.F., Warren, P.H. \& Woodward, G. (2009) Ecological networks - beyond food webs. Journal of Animal Ecology, 78, 253-269.

Karjalainen, S. (2010) Suomen sudenkorennot. Tammi, Helsinki.

Kaunisto, K.M., Roslin, T., Saaksjarvi, I.E. \& Vesterinen, E.J. (2017) Pellets of proof: First glimpse of the dietary composition of adult odonates as revealed by metabarcoding of feces. Ecology and Evolution, 7, 8588-8598.

Lamb, P.D., Ewan Hunter, John K. Pinnegar, Simon Creer, Richard G. Davies, and Martin I. Taylor (2019) How Quantitative Is Metabarcoding: A Meta - analytical Approach. Molecular Ecology, 28, 420-430.

Lebreton, J.D., Burnham, K.P., Clobert, J. \& Anderson, D.R. (1992) Modeling survival and testing biological hypotheses using marked animals - a unified approach with case-studies. Ecological Monographs, 62, 67-118.

Legendre, P. \& Legendre, L. (2012) Numerical Ecology. Elsevier, Amsterdam.

Maine, J.J. \& Boyles, J.G. (2015) Bats initiate vital agroecological interactions in corn. Proceedings of the National Academy of Sciences of the United States of America, 112, 12438-12443.

Mantyla, E., Klemola, T. \& Laaksonen, T. (2011) Birds help plants: a meta-analysis of topdown trophic cascades caused by avian predators. Oecologia, 165, 143-151.

Mayhew, P.J. (1994) Food intake and adult feeding behaviour in Calopteryx splendens (Harris) and Erythromma najas (Hansemann) (Zygoptera: Calopterygidae, Coenagrionidae). Odonatologica, 2, 115-124.

McVey, M.E. (1985) Rates of color maturation in relation to age, diet, and temperature in male Erythemis simplicicollis (Say) (Anisoptera: Libellulidae). Odonatologica, 14, 101-114.

Montoya, J.M., Woodward, G., Emmerson, M.C. \& Sole, R.V. (2009) Press perturbations and indirect effects in real food webs. Ecology, 90, 2426-2433.

Mooney, K.A., Gruner, D.S., Barber, N.A., Van Bael, S.A., Philpott, S.M. \& Greenberg, R. (2010) Interactions among predators and the cascading effects of vertebrate insectivores on arthropod communities and plants. Proceedings of the National Academy of Sciences of the United States of America, 107, 7335-7340.

Pettersen, A.K., White, C.R., Bryson-Richardson, R.J. \& Marshall, D.J. (2019) Linking lifehistory theory and metabolic theory explains the offspring size-temperature relationship. Ecology Letters, 22, 518-526.

Pinol, J., San Andres, V., Clare, E.L., Mir, G. \& Symondson, W.O.C. (2014) A pragmatic approach to the analysis of diets of generalist predators: the use of nextgeneration sequencing with no blocking probes. Molecular Ecology Resources, 14, 18-26.

Pocock, M.J.O., Evans, D.M. \& Memmott, J. (2012) The Robustness and Restoration of a Network of Ecological Networks. Science, 335, 973-977.

Roslin, T. \& Majaneva, S. (2016) The use of DNA barcodes in food web constructionterrestrial and aquatic ecologists unite! Genome, 59, 603-628.

Roslin, T., Traugott, M., Jonsson, M., Stone, G.N., Creer, S. \& Symondson, W.O.C. (2019) Introduction: Special issue on species interactions, ecological networks and community dynamics - Untangling the entangled bank using molecular techniques. Molecular Ecology, 28, 157-164. 
Royama, T. (2012) Analytical population dynamics. Springer Science \& Business Media. Rytkönen, S., E. J. Vesterinen, C. Westerduin, T. Leviäkangas, E. Vatka, M. Mutanen, P. Välimäki, M. Hukkanen, M. Suokas, M. Orell (2019) From feces to data: A metabarcoding method for analyzing consumed and available prey in a birdinsect food web. Ecology and Evolution, 9, 631-639.

Schmitz, O.J. \& Suttle, K.B. (2001) Effects of top predator species on direct and indirect interactions in a food web. Ecology, 82, 2072-2081.

Siepielski, A.M., Hung, K.L., Bein, E.E.B. \& McPeek, M.A. (2010) Experimental evidence for neutral community dynamics governing an insect assemblage. Ecology, 91, 847-857.

Stenseth, N.C., Falck, W., Bjornstad, O.N. \& Krebs, C.J. (1997) Population regulation in snowshoe hare and Canadian lynx: Asymmetric food web configurations between hare and lynx. Proceedings of the National Academy of Sciences of the United States of America, 94, 5147-5152.

Thompson, R.M., Brose, U., Dunne, J.A., Hall, R.O., Hladyz, S., Kitching, R.L., Martinez, N.D., Rantala, H., Romanuk, T.N., Stouffer, D.B. \& Tylianakis, J.M. (2012) Food webs: reconciling the structure and function of biodiversity. Trends in Ecology \& Evolution, 27, 689-697.

Van Allen, B.G., Rasmussen, N.L., Dibble, C.J., Clay, P.A. \& Rudolf, V.H.W. (2017) Top predators determine how biodiversity is partitioned across time and space. Ecology Letters, 20, 1004-1013.

Van Bael, S.A., Brawn, J.D. \& Robinson, S.K. (2003) Birds defend trees from herbivores in a Neotropical forest canopy. Proceedings of the National Academy of Sciences of the United States of America, 100, 8304-8307.

Vesterinen, E.J., Lilley, T., Laine, V.N. \& Wahlberg, N. (2013) Next Generation Sequencing of Fecal DNA Reveals the Dietary Diversity of the Widespread Insectivorous Predator Daubenton's Bat (Myotis daubentonii) in Southwestern Finland. Plos One, 8.

Vesterinen, E.J., Puisto, A.I.E., Blomberg, A.S. \& Lilley, T.M. (2018) Table for five, please: Dietary partitioning in boreal bats. Ecology and Evolution, 8, 10914-10937.

Visakorpi, K., Wirta, H.K., Ek, M., Schmidt, N.M. \& Roslin, T. (2015) No detectable trophic cascade in a high-Arctic arthropod food web. Basic and Applied Ecology, 16, 652660.

Williams, R.J. \& Martinez, N.D. (2000) Simple rules yield complex food webs. Nature, 404, 180-183.

Wirta, H.K., Vesterinen, E.J., Hamback, P.A., Weingartner, E., Rasmussen, C., Reneerkens, J., Schmidt, N.M., Gilg, O. \& Roslin, T. (2015) Exposing the structure of an Arctic food web. Ecology and Evolution, 5, 3842-3856.

Yodzis, P. \& Innes, S. (1992) Body size and consumer-resource dynamics. American Naturalist, 139, 1151-1175.

Zeale, M.R.K., Butlin, R.K., Barker, G.L.A., Lees, D.C. \& Jones, G. (2011) Taxon-specific PCR for DNA barcoding arthropod prey in bat faeces. Molecular Ecology Resources, 11, 236-244. 


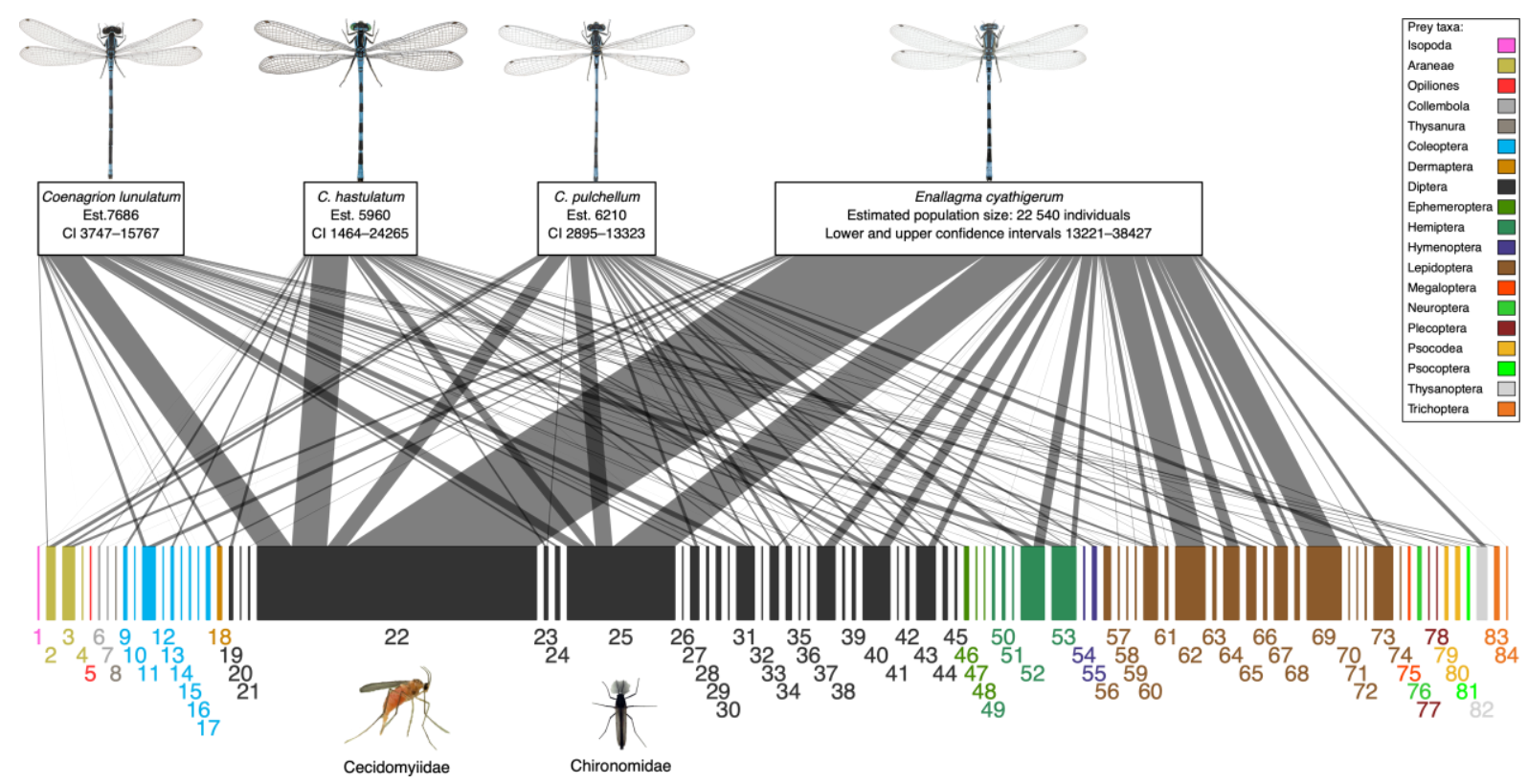

3 Figure 1. Visual representation of the taxonomic distribution and quantified strength of

4 trophic links from each of our four focal odonate species to their prey. The blocks in the

5 upper row represent predators, with their size scaled to represent the estimated population

6 size. The blocks in the lower row represent prey families, with two most common prey

7 families highlighted. A line connecting a predator with a prey represents detected predation

8 events, and the thickness of the line represents the relative read abundance (RRA) of each

9 predation record (Supplementary material S1, Detailed material and methods: Eqn S1). See

10 the "Data analysis" in the main text for details on the RRA. The numbers below the lower

11 blocks correspond to the prey family numbers (Supplementary material S1: Table S4). Photo

12 credits: Göran Liljeberg \& Hallvard Elven, Artdatabanken.no (CC BY-SA 3.0, Odonata),

13 Hallvard Elven, Artdatabanken.no (CC BY-SA 4.0, Cecidomyiidae, modified); František

14 Šaržík, biolibs.cz (CC-BY, Chironomidae, modified). 